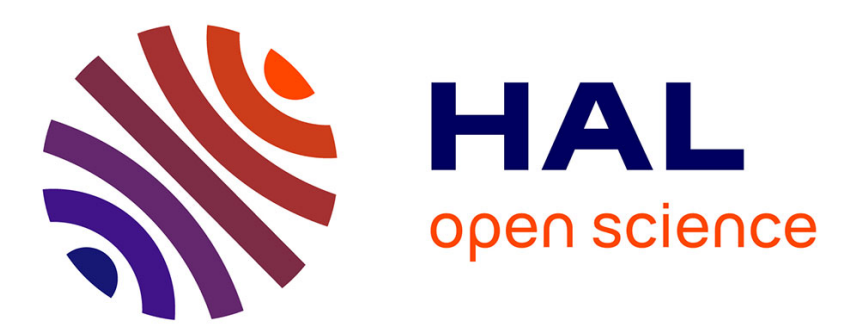

\title{
Simulation and tomography analyzis of textile composite reinforcement deformation at the mesoscopic scale
}

\author{
P. Badel, E. Vidal-Sallé, E. Maire, P. Boisse
}

\section{To cite this version:}

P. Badel, E. Vidal-Sallé, E. Maire, P. Boisse. Simulation and tomography analyzis of textile composite reinforcement deformation at the mesoscopic scale. Composites Science and Technology, 2009, 68 (12), pp.2433. 10.1016/j.compscitech.2008.04.038 . hal-00594919

\section{HAL Id: hal-00594919 \\ https://hal.science/hal-00594919}

Submitted on 22 May 2011

HAL is a multi-disciplinary open access archive for the deposit and dissemination of scientific research documents, whether they are published or not. The documents may come from teaching and research institutions in France or abroad, or from public or private research centers.
L'archive ouverte pluridisciplinaire HAL, est destinée au dépôt et à la diffusion de documents scientifiques de niveau recherche, publiés ou non, émanant des établissements d'enseignement et de recherche français ou étrangers, des laboratoires publics ou privés. 


\section{Accepted Manuscript}

Simulation and tomography analyzis of textile composite reinforcement defor mation at the mesoscopic scale

P. Badel, E. Vidal-Sallé, E. Maire, P. Boisse

PII: S0266-3538(08)00148-6

DOI: 10.1016/j.compscitech.2008.04.038

Reference:

CSTE 4038

To appear in:

Composites Science and Technology

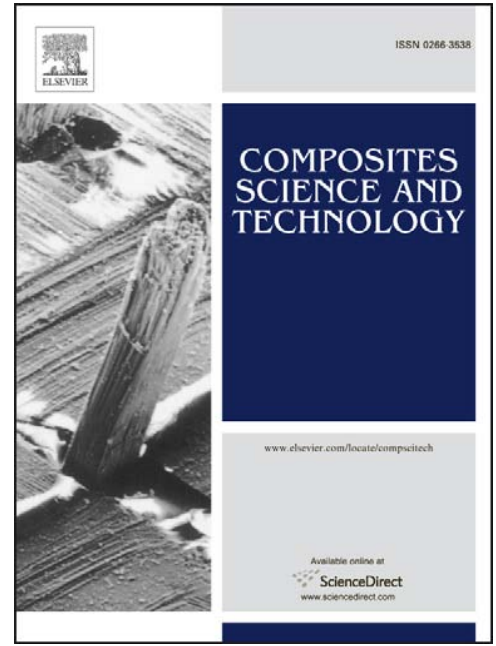

Received Date: $\quad 5$ February 2008

Revised Date: $\quad 10$ April 2008

Accepted Date: $\quad 13$ April 2008

Please cite this article as: Badel, P., Vidal-Sallé, E., Maire, E., Boisse, P., Simulation and tomography analyzis of textile composite reinforcement deformation at the mesoscopic scale, Composites Science and Technology (2008), doi: 10.1016/j.compscitech.2008.04.038

This is a PDF file of an unedited manuscript that has been accepted for publication. As a service to our customers we are providing this early version of the manuscript. The manuscript will undergo copyediting, typesetting, and review of the resulting proof before it is published in its final form. Please note that during the production process errors may be discovered which could affect the content, and all legal disclaimers that apply to the journal pertain. 


\title{
SIMULATION AND TOMOGRAPHY ANALYZIS OF TEXTILE COMPOSITE REINFORCEMENT DEFORMATION AT THE MESOSCOPIC SCALE
}

\author{
P. Badel ${ }^{\text {a }}$, E. Vidal-Sallé ${ }^{\mathrm{a}}$, E. Maire $^{\mathrm{b}}$, P. Boisse ${ }^{\mathrm{a}, *}$
}

(a) Laboratoire de Mécanique des Contacts et des Structures, INSA-Lyon, France

(b) Laboratoire Matériaux : Ingénierie et Sciences, INSA-Lyon, France

\begin{abstract}
The preforming stage of the RTM composite manufacturing process leads to fibrous reinforcement deformations which may be very large especially for double curvature shapes. The knowledge of the mesoscopic deformed geometry is important for reinforcement permeability computations and for damage prediction analyzes of the composite. A simulation method for woven composite fabric deformation at mesoscopic scale is presented in this paper. A specific continuum hypo-elastic constitutive model is proposed for the yarn behavior. The associated objective derivative is based on the fiber rotation. Spherical and deviatoric parts of the transverse behavior are uncoupled. X-ray tomography is used to obtain experimental undeformed and deformed 3D geometries of the textile reinforcements. It provides, in particular, fiber distribution within the yarn. A comparison between deformed geometries obtained by mesoscopic simulation and by tomography is presented for bi-axial tension and in-plane shear deformation.
\end{abstract}

Keywords: A. Textile composites ; B. Mechanical properties ; C. Finite element analysis (FEA) ; E. Resin transfer moulding (RTM) ; X-Ray Tomography

\footnotetext{
* Corresponding author: phone: (33) 4724363 96; E-mail: Philippe.Boisse@ insalyon.fr
} 


\section{ACCEPTED MANUSCRIPT}

\section{Introduction}

The RTM (Resin Transfer Moulding) process for composite material forming consists of three stages. A dry textile reinforcement is formed (preforming stage), then the resin is injected within this preform and cured to obtain the final composite part [13]. If the shape of the composite part is double curved, the textile reinforcement is subjected to in-plane deformation in order to reach this shape. These deformations can be significant, especially in-plane shear that can reach $40^{\circ}$ or $50^{\circ}$ (see Fig. 1) [4,5]. Preform deformation at the scale of the composite part (macroscopic scale) corresponds to local deformation of the fibrous network (mesoscopic scale) which can be large particularly when it is woven. This deformation modifies the mechanical properties and the permeability of the reinforcement.

The objective of this paper is to present a method for the simulation of the deformation of a woven composite reinforcement representative unit cell (i.e. at the mesoscopic scale). These simulations enable to determine the macroscopic scale mechanical behavior of composite reinforcements (without resin) at finite strain. This mechanical behavior is required in finite element simulations of the preforming stage [6-13]. Besides, knowing the deformed geometry of the woven cell enables to determine the permeability of the fibrous reinforcement via Stokes (or Stokes Brinkman) flow simulations within this deformed cell [14-18]. Finally, the geometry of the deformed reinforcement heavily influences the mechanical behavior of the final composite part. In particular, meso-scale damage prediction simulations require the knowledge of this geometry [19-23].

The local geometry of the woven reinforcement can be determined experimentally using X-ray tomography. The advantage of tomography is to give access to local 3D observations inside the sample $[24,25]$ which is not possible with the standard 


\section{ACCEPTED MANUSCRIPT}

microscopy techniques restrained to surface observations. X-ray tomography is used in the present paper at a mesoscopic scale (the scale of the yarns) to determine the initial and deformed geometry of fibrous composite reinforcements and at a microscopic scale (the scale of the fibers) to determine the density and distribution of fibers within the yarn. The information gathered from these experiments is used to improve and justify the hypotheses made during the development of the mechanical constitutive model and above all to validate the results obtained from simulation.

In the present paper, the yarn is assumed to be a continuum. The mechanical behavior of this continuum is very specific since the yarn is made up of thousands of fibers which can slide with respect to each other. The suggested constitutive model is hypo-elastic [26-29]. The objective derivative of this model is defined from the local fiber rotation so that it accurately tracks the fiber direction. The transverse behavior of the yarns is of a great importance because local crushing of the yarns is significant during the deformation. It will be shown in section 2.3 and 3.1 that the X-ray tomography observations support the fact that the behavior of the yarn can be assumed to be transversely isotropic. Spherical and deviatoric parts are separated in the transverse constitutive model. In section 4, the mesoscopic deformed geometries of the unit cell under biaxial tension and large in-plane shear $\left(46^{\circ}\right)$ are compared to the experimental geometries obtained by tomography. The agreement is good.

\section{X-ray tomography of the studied composite reinforcements}

\subsection{Principle of the technique}

The principle of X-ray tomography is explained in details in [24]. This technique is analogous to the medical scanner and allows from X-ray radiography reconstructing non destructively the internal structure of an opaque material. The reconstruction involves a computed step and the final image is a 3D map of the local X-ray attenuation 


\section{ACCEPTED MANUSCRIPT}

coefficient. The fibers absorbing much more the X-rays than air, the attenuation contrast allows a straightforward subsequent thresholding of the images.

The laboratory tomograph used in the present study is a commercial model [30] located in the Mateis Laboratory at Université de Lyon. It includes a nanofocus transmission X-ray tube (W target). The size of the focus (and thus the resolution) is tunable from 1 to 5 microns. The detector used is a 1500x1900 array of amorphous silicon sensible elements each of a lateral size of $127 \times 127$ microns. The beam has been operated at $90 \mathrm{keV}$ and $170 \mu \mathrm{A}$ with no filtering for the observations made in this study. The setup used exhibiting a cone beam geometry, it is easy to obtain images at different values of the magnification. For this purpose, the sample is simply placed at different distances from the source leading to a possible voxel size of 1.5 to 80 microns in the resulting reconstruction. The highest resolution achieved in this study is $2.85 \mu \mathrm{m}$ because of the trade-off between the resolution and the maximum specimen dimension (i.e. yarn width). The complete sample must be contained indeed within the cone beam i.e. in the field of view of the detector.

The uncertainty of the measures made by tomography can be estimated to \pm 1 voxel.

\subsection{Samples, resolution and experimental results}

Thanks to the above mentioned flexibility, the woven composite fabrics have been analyzed at two different scales namely the mesoscopic scale and the microscopic scale. Undeformed geometries but also deformed geometries of interest in this study can be analyzed. Three types of woven reinforcements are shown (see table 1). The first one is a complex interlock reinforcement hereafter referred to as G1151. The interest of an interlock structure is to tie several layers together. Its large unit cell is reconstructed with a resolution of 20 microns (see Fig. 2). The reconstruction of an unloaded 2x2 carbon twill (10 $\mu \mathrm{m}$ resolution) and a glass plain weave in both undeformed ( $3 \mu \mathrm{m}$ 


\section{ACCEPTED MANUSCRIPT}

resolution) and deformed states ( $3 \mu \mathrm{m}$ and $20 \mu \mathrm{m}$ resolution) are also used in the paper.

Fig. 2 to 4 show several reconstructed slices of these reinforcements and also 3D views after removing the voxels belonging to the air phase. These 3D views are close to what can be observed visually. The 3D nature of the data allows performing virtual cuts as examplified in Figs. 2 and 7.

The images of the undeformed interlock reinforcement underline the complexity of the woven structure characterized by non trivial initial geometries (Fig. 2). One can for instance observe that even in the undeformed case, superimposed weft yarns generally don't lie in the same plane and that a wide variety of cross section shapes can be observed on a single yarn depending on the location inside the fabric (especially for warp yarns, see Fig. 2b). These cross sections can be elliptic, almost flat, or quasi rectangular in some cases. These observations can be used for geometric modeling of such reinforcements. The reconstructed slices of the carbon twill as well as the glass plain weave under biaxial tension (see Fig. 3) can be used to study the outer shape of the cross sections of the yarns and their trajectory in the purpose of validating mesoscopic scale simulations of the deformation of a reinforcement. This will be addressed in section 4.

In this paper, only the plain weave is studied from both the tomography and the computational analyses (section 4). For the other two reinforcements, only the qualitative images are shown. The observations and remarks that have been made are helpful for the development of geometric models and could be used directly in subsequent work or by other authors.

\subsection{Quantification of the spatial distribution of the fibers inside the yarns}

The images at the microscopic scale provide additional information about the location of fibers, their relative position or the spatial distribution of their local density. 


\section{ACCEPTED MANUSCRIPT}

From the comparison of Figs. $4 \mathrm{a}, 4 \mathrm{~b}$ and $4 \mathrm{c}$ it can be noticed that the fiber bundle tends to be denser in the deformed state (either biaxial tension or shear) though the distribution appears visually to be at random in each of the three cases. The quantitative analyzis of the morphology of these images was performed according to a procedure described in [31] and also used in [32] for other types of microstructures. This procedure requires the calculation of the two point covariance of binary images of the microstructure. The covariance $\mathrm{C}(\mathrm{x})$ is the probability for two points, separated by the distance $\mathrm{x}$, to belong to the same phase, namely the phase of the fibers in this paper. Although three dimensional in nature, the microstructure of the bundles is well known in the fiber direction, so only cross sectional images were used here. When calculated in two perpendicular directions (namely along the width and along the thickness of each yarn), the covariograms provide information about the spatial distribution of fibers within the yarn. If the covariograms look similar in the two directions, the sample can be assumed to be isotropic. In the present paper, these covariograms are calculated from a series of relatively fast operations involving Fourier and inverse Fourier transforms of the 2D images (see [31] for more details). Fig. 5 presents the curves of the covariance in directions 2 and 3 averaged over several measurements, each performed on four different yarn cross sections and at twenty-two different locations containing about 70 fibers in each case. This analysis has been performed from sheared reinforcement tomography scans. The result is similar when using a specimen under biaxial tension. However, it is not performed for an undeformed fabric because the strong variability of the undeformed state and the initial dispersion of the fiber distribution make the covariograms unusable.

The curves show that the first minimum (corresponding to the average position of the air gap between two fibers) and the first maximum (a measure of the average position of 


\section{ACCEPTED MANUSCRIPT}

the first neighboring fiber) of the curves are located at similar distances in both directions indicating an isotropic spacing of the fibers. The slight difference of the covariograms is attributed to reconstruction artifacts due to the strong anisotropy of the objects. Indeed, fluctuations of the average gray level (visible in Fig. 4c for instance) induce thresholding differences and modify the covariograms at long distances. Apart from this artifact, the set of observations and measurements made in this section is a strong support to validate the subsequent hypothesis of a quasi-isotropic distribution of the fibers in the transverse plane during the deformation of a bundle.

\section{Mesoscopic mechanical analyzis of woven reinforcements}

The objective of the present section is to perform a mesoscopic analyzis of woven textile reinforcement deformations. Deformed geometries are required in many applications such as permeability simulations, composite damage prediction... To this aim a constitutive model of the composite reinforcement during the forming is to be introduced. This model has to convey the specificities of the fibrous material of the yarns. Among them, the large longitudinal stiffness of the fibers compared to the other rigidities, which requires to accurately track the fiber direction, and the transverse behavior of the yarns, which is of a great importance for the deformed shape, are two crucial aspects for mesoscopic analyzes of woven reinforcements which will be presented afterwards.

\subsection{Constitutive model}

The constitutive model is written within the framework of a rate constitutive equation (or hypo-elasticity) [26-29, 33-35]. The mechanical behavior of the yarn is assumed to be transversely isotropic in the direction perpendicular to that of the fibers, hereafter denoted as $\underline{\mathbf{f}}_{1}$. This hypothesis is hard to verify experimentally, nevertheless from the preceding section, it is clear that the microstructure is rather isotropic. It can be 


\section{ACCEPTED MANUSCRIPT}

noted that some work on rather different systems i.e. particular reinforced composites had already shown that if the spatial distribution of the reinforcement of a composite is at random and thus isotropic, the isotropy tends to be preserved after deformation.

Although a slight anisotropy could be measured by precise image processing, the effect on the mechanical properties was found to be undetectable in [36]. Thus the assumption of transverse mechanical isotropy for the yarn behavior is reasonable. In this section the two important aspects of the constitutive model are addressed: the longitudinal and transverse behaviors.

A hypo-elastic constitutive equation (or rate constitutive equation) [26-28] has the following form:

$$
\underline{\underline{\boldsymbol{\sigma}}}^{\nabla}=\underline{\underline{\underline{\mathbf{C}}}}: \underline{\underline{\mathbf{D}}}
$$

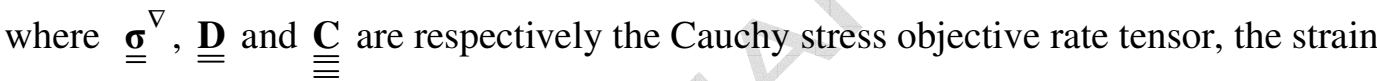
rate tensor and the constitutive tensor. In this work, the constitutive tensor is assumed to depend only on the strain state of the fiber bundle because only monotonic loadings are considered (no cyclic loading). Equation (1) is integrated over a time increment $\Delta \mathrm{t}=\mathrm{t}^{\mathrm{n}+1}-\mathrm{t}^{\mathrm{n}}$ using the formula of Hughes and Winget widely used in finite element codes at finite strains [33-35]:

$$
\left[\boldsymbol{\sigma}^{\mathrm{n}+1}\right]_{\mathrm{e}_{\mathrm{i}}^{\mathrm{n}+1}}=\left[\boldsymbol{\sigma}^{\mathrm{n}}\right]_{\mathrm{e}_{\mathrm{i}}^{\mathrm{n}}}+\left[\mathbf{C}^{\mathrm{n}+1 / 2}\right]_{\mathrm{e}_{\mathrm{i}}^{\mathrm{n}+1 / 2}}[\Delta \boldsymbol{\varepsilon}]_{\mathrm{e}_{\mathrm{i}}^{\mathrm{n}+1 / 2}}
$$

where $[\Delta \boldsymbol{\varepsilon}]_{\mathrm{e}_{i}^{n+1 / 2}}=[\mathbf{D}]_{\mathrm{e}_{\mathrm{i}}^{\mathrm{n}+1 / 2}} \Delta \mathrm{t}$ and $[\mathbf{S}]_{\mathrm{e}_{\mathrm{i}}^{\mathrm{n}}}$ stands for the matrix of the components of any tensor $\underline{\underline{\mathbf{S}}}$ expressed in the basis $\underline{\mathbf{e}}_{\mathrm{i}} \otimes \underline{\mathbf{e}}_{\mathrm{j}} \otimes \ldots \otimes \underline{\mathbf{e}}_{\mathrm{m}}$ at time $\mathrm{t}^{\mathrm{n}} .\left\{\underline{\mathbf{e}}_{\mathrm{i}}\right\}=\left\{\underline{\mathbf{e}}_{1}, \underline{\mathbf{e}}_{2}, \underline{\mathbf{e}}_{3}\right\}$ is the orthonormal rotating basis, the rotation of which is used to compute the objective derivatives. The first main aspect of the constitutive model of the yarn is tackled through this equation. Indeed the very large longitudinal stiffness of the fibers requires to strictly monitor their direction under the risk of cumulating significant spurious 
stresses at each time step. Therefore the rotating basis, denoted as $\left\{\underline{\mathbf{f}}_{\mathrm{i}}\right\}$ in the present case of a fibrous material, must be attached to $\underline{\mathbf{f}}_{1}$ the fiber direction, which means using a rotational objective derivative based on the fiber rotation $[37,38]$ :

$$
\left[\boldsymbol{\sigma}^{\mathrm{n}+1}\right]_{\mathrm{f}_{\mathrm{i}}^{\mathrm{n}+1}}=\left[\boldsymbol{\sigma}^{\mathrm{n}}\right]_{\mathrm{f}_{\mathrm{i}}^{\mathrm{n}}}+\left[\mathbf{C}^{\mathrm{n}+1 / 2}\right]_{\mathrm{f}_{\mathrm{i}}^{\mathrm{n}+1 / 2}}[\Delta \boldsymbol{\varepsilon}]_{\mathrm{f}_{\mathrm{i}}^{\mathrm{n}+1 / 2}}
$$

The other two vectors $\underline{\mathbf{f}}_{2}$ and $\underline{\mathbf{f}}_{3}$ of the rotating basis must follow rigid body motions. $\underline{\mathbf{f}}_{2}$ is defined as the projection of its materially convected initial position into the plane perpendicular to $\underline{\mathbf{f}}_{1}$. The basis $\left\{\underline{\mathbf{f}}_{\mathrm{i}}\right\}$ is direct and orthonormal. In equation (3) the constitutive matrix $[\mathbf{C}]_{\mathrm{f}_{\mathrm{i}}}$ is expressed in the basis $\left\{\underline{\mathbf{f}}_{\mathrm{i}}\right\}$ oriented by the fibers at current time. This is a major advantage because its shape and its components are known or can be determined in this basis where longitudinal and transverse behaviors are distinguished. The first one is defined by the stiffness of the fibers in direction $\underline{\mathbf{f}}_{1}$ (which can be determined by simple mechanical tests on a single yarn) whereas the second one characterizes the behavior of the fiber bundle in the plane $\left(\underline{\mathbf{f}}_{2}, \underline{\mathbf{f}}_{3}\right)$.

The latter is an important issue for mesoscopic analyzes, it accounts for shape changes of the yarn cross section. As it will be seen in the following, the yarns tend to be transversely crushed in any type of solicitation. These local effects play a major role for the macroscopic mechanical behavior of the reinforcement. It is suggested in the present approach to uncouple "spherical" and deviatoric phenomena within the transverse plane (in two dimensions, the term "spherical" is a misuse of language, but we use it for convenience in the following). This separation is illustrated by tomography scans where two modes of deformation of the cross section are clearly distinguished: compaction of the network of fibers (for instance in biaxial tension, Fig 4b) and rearrangement or change of shape of the fiber bundle (noticeable in pure shear, Fig 4c). These two modes correspond to spherical and deviatoric transformations of the cross 


\section{ACCEPTED MANUSCRIPT}

section: the spherical part of the deformation is related to the fiber density changes and the deviatoric part to the shape changes.

In the following, it is assumed that these two modes are uncoupled, which remains valid under the assumption of isotropy made in the plane $\left(\underline{\mathbf{f}}_{2}, \underline{\mathbf{f}}_{3}\right)$. Let us separate longitudinal and transverse deformations within the strain tensor:

$$
[\boldsymbol{\varepsilon}]_{\mathrm{f}_{\mathrm{i}}}=\left[\begin{array}{ccc}
\varepsilon_{11} & \varepsilon_{12} & \varepsilon_{13} \\
& 0 & 0 \\
\text { sym. } & & 0
\end{array}\right]+\left[\begin{array}{ccc}
0 & 0 & 0 \\
& \varepsilon_{22} & \varepsilon_{23} \\
\text { sym. } & & \varepsilon_{33}
\end{array}\right]=\left[\boldsymbol{\varepsilon}_{\mathrm{L}}\right]_{\mathrm{f}_{\mathrm{i}}}+\left[\boldsymbol{\varepsilon}_{\mathrm{T}}\right]_{\mathrm{f}_{\mathrm{i}}}
$$

where $\underset{\underline{\varepsilon}}{\boldsymbol{\varepsilon}}$, in this paper, stands for the tensorial cumulation of $\underline{\underline{\mathbf{D}} \Delta \mathrm{t}}$ in the rotating frame.

The following developments only concern the plane $\left(\underline{\mathbf{f}}_{2}, \underline{\mathbf{f}}_{3}\right)$ and the restriction of $\left[\boldsymbol{\varepsilon}_{\mathrm{T}}\right]_{\mathrm{f}_{\mathrm{i}}}$ to $\left(\underline{\mathbf{f}}_{2}, \underline{\mathbf{f}}_{3}\right)$ (denoted with a tilde) is considered :

$$
\left[\tilde{\boldsymbol{\varepsilon}}_{\mathrm{T}}\right]_{\mathrm{f}_{\mathrm{i}}}=\left[\begin{array}{cc}
\varepsilon_{22} & \varepsilon_{23} \\
\text { sym. } & \varepsilon_{33}
\end{array}\right]
$$

The separation of $\left[\tilde{\boldsymbol{\varepsilon}}_{\mathrm{T}}\right]_{\mathrm{f}_{\mathrm{i}}}$ in spherical and deviatoric parts can be written in the following way:

$$
\left[\tilde{\boldsymbol{\varepsilon}}_{\mathrm{T}}\right]_{\mathrm{f}_{\mathrm{i}}}=\left[\begin{array}{cc}
\varepsilon_{\mathrm{s}} & 0 \\
0 & \varepsilon_{\mathrm{s}}
\end{array}\right]+\left[\begin{array}{cc}
\varepsilon_{\mathrm{d}} & \varepsilon_{23} \\
\varepsilon_{23} & -\varepsilon_{\mathrm{d}}
\end{array}\right]
$$

where $\varepsilon_{\mathrm{s}}=\frac{\varepsilon_{22}+\varepsilon_{33}}{2}$ is the spherical strain component and $\varepsilon_{\mathrm{d}}=\frac{\varepsilon_{22}-\varepsilon_{33}}{2}, \varepsilon_{23}$ are the deviatoric ones. This formalism where spherical and deviatoric parts are uncoupled is very often used in plasticity models. It has also been used in fiber bundle micromechanics in $[39,40]$.

For the moment, the model is considered as (non linear) elastic then the same separation is valid for stresses. Moreover, since integration is a linear operation, this separation also holds for strain and stress increments $\left[\Delta \boldsymbol{\varepsilon}_{\mathrm{T}}\right]_{\mathrm{f}_{\mathrm{i}}}$ and $\left[\Delta \boldsymbol{\sigma}_{\mathrm{T}}\right]_{\mathrm{f}_{\mathrm{i}}}$. Thus the suggested uncoupling leads to the following relations: 


$$
\begin{aligned}
& \Delta \sigma_{\mathrm{s}}=\mathrm{A} \Delta \varepsilon_{\mathrm{s}} \\
& \Delta \sigma_{\mathrm{d}}=\mathrm{B} \Delta \varepsilon_{\mathrm{d}} \\
& \Delta \sigma_{23}=\mathrm{C} \Delta \varepsilon_{23}
\end{aligned}
$$

where $\Delta \sigma_{\mathrm{s}}, \Delta \sigma_{\mathrm{d}}, \Delta \varepsilon_{\mathrm{s}}$ and $\Delta \varepsilon_{\mathrm{d}}$ are respectively spherical and deviatoric stress and strain increments (stress components being defined in the same way as strain components by eq. (6)), and A, B, C are the elastic coefficients. It can be shown that $\mathrm{B}=\mathrm{C}$. Eventually the transverse constitutive tensor (used in equation (3)) contains two independent elastic coefficients, which corresponds to an isotropic two dimensional medium: (using Voigt notation):

$$
\left[\tilde{\mathbf{C}}_{\mathrm{T}}\right]_{\mathrm{f}_{\mathrm{i}}}=\left[\begin{array}{ccc}
(\mathrm{A}+\mathrm{B}) / 2 & (\mathrm{~A}-\mathrm{B}) / 2 & 0 \\
(\mathrm{~A}-\mathrm{B}) / 2 & (\mathrm{~A}+\mathrm{B}) / 2 & 0 \\
0 & 0 & \mathrm{~B}
\end{array}\right]
$$

To complete the description of this model, the form of the coefficients A and B must be specified. To this aim, we use basic physical assumptions. Under compaction the material becomes stiffer in both spherical and deviatoric behaviors due to a densification of the fiber network (up to the maximum achievable density). Note also that under longitudinal tension, the spherical behavior should be stiffer. The transverse compaction of a fiber bundle requires more effort under pre-tension. The influence of longitudinal tension on the deviatoric behavior is not as easy to anticipate but can be assumed to be weak. For the sake of simplicity, it is considered in the present model that tension has no influence on the deviatoric behaviour. From these assumptions, it is suggested to give the following form to coefficients A and B:

$$
\begin{aligned}
& A=A_{0} e^{-p \varepsilon_{s}} e^{n \varepsilon_{11}} \\
& B=B_{0} e^{-p \varepsilon_{s}}
\end{aligned}
$$

Finally, the transverse constitutive model requires four parameters. The proposed model is elastic but due to the uncoupling between spherical and deviatoric parts it could be extended to elasto-plasticity. 


\section{ACCEPTED MANUSCRIPT}

The material coefficients of the yarn constitutive tensor are determined from different experimental tests. The longitudinal Young modulus $\mathrm{E}_{1}$ is known from a tension test on a single yarn. The determination of the transverse behavior four parameters $\mathrm{A}_{0}, \mathrm{~B}_{0}, \mathrm{n}$ and $\mathrm{p}$ is performed through an inverse method [41] based on a test that leads to significantly crushing the yarns. Equi-biaxial tension tests [5] fulfill this requirement and are used in this work. Eventually, to keep the yarn bending stiffness low, the longitudinal shear moduli $\mathrm{G}_{12}$ and $\mathrm{G}_{13}$ are significantly lower than the longitudinal Young's modulus [42] and assumed to have equal values: $\mathrm{G}_{12}=\mathrm{G}_{13}=\mathrm{G}_{1}$. Longitudinal Poisson ratios are assumed to be null. Eventually the constitutive matrix has the following shape:

$$
[\mathbf{C}]_{\mathrm{f}_{\mathrm{i}}}=\left[\begin{array}{cccccc}
\mathrm{E}_{1} & 0 & 0 & 0 & 0 & 0 \\
& (\mathrm{~A}+\mathrm{B}) / 2 & (\mathrm{~A}-\mathrm{B}) / 2 & 0 & 0 & 0 \\
& & (\mathrm{~A}+\mathrm{B}) / 2 & 0 & 0 & 0 \\
& & & \mathrm{G}_{1} & 0 & 0 \\
& & & \mathrm{~B} & 0 \\
& & & & & \mathrm{G}_{1}
\end{array}\right]
$$

\subsection{Mesoscopic simulations of reinforcement deformation}

This section addresses the way to perform mesoscopic scale simulations of the mechanical behavior of composite reinforcements. First the geometry of the model has to be defined. It must insure that there are neither unexpected penetrations nor spurious voids between the yarns. The results of Hivet [43] provide a convenient and ready-touse way to deal with this issue, they are thus used to generate the meshes of the yarns.

Second the periodicity of the reinforcement is used to set the size of the geometric model. The smallest geometry to be modeled is that of a representative unit cell of the reinforcement, i.e. the smallest pattern permitting reconstructing the whole fabric by translations only. Its choice is not unique. Nevertheless considering the application of boundary conditions, the choice of a unit cell with material boundaries is preferred (see 


\section{ACCEPTED MANUSCRIPT}

the deformed cell, Fig. 7). In some particular cases like biaxial tension tests, the symmetry properties of the reinforcement and the test kinematics allow reducing the size of the model. This is not the case for pure shear because the symmetries of the geometry vanish due to the kinematics of shear. The periodicity of the reinforcement must be guaranteed during the test, which is achieved through appropriate boundary conditions. Due to periodicity, the displacement field is in the form:

$$
\underline{\varphi}(\underline{\mathbf{X}})=\underline{\varphi_{\mathrm{m}}}(\underline{\mathbf{X}})+\underline{\mathbf{w}}(\underline{\mathbf{X}})
$$

with $\underline{\varphi_{\mathrm{m}}}$ denoting the macroscopic (known) displacement field, and $\underline{\mathbf{w}}$ the periodic (unknown) local displacement field. Considering two points of the boundary, $\underline{\mathbf{X}}$ and $\underline{\mathbf{X}}^{\prime}$, which are images of each other by virtue of periodicity, and using the periodicity condition $\underline{\mathbf{w}}(\underline{\mathbf{X}})=\underline{\mathbf{w}}\left(\underline{\mathbf{X}}^{\prime}\right)$, one obtains the kinematical boundary conditions for the model:

$$
\underline{\varphi}\left(\underline{\mathbf{X}}^{\prime}\right)-\underline{\varphi}(\underline{\mathbf{X}})=\underline{\varphi_{\mathrm{m}}}\left(\underline{\mathbf{X}}^{\prime}\right)-\underline{\varphi_{\mathrm{m}}}(\underline{\mathbf{X}})
$$

This equation consists of a set of relationships between the displacement degrees of freedom of each pair $\underline{\mathbf{X}}, \underline{\mathbf{X}}^{\prime}$ of the boundary. In the following, $\underline{\varphi}_{\mathrm{m}}$ will consist of either a pure shear displacement field $\left(\mathrm{u}_{\mathrm{x}}=\mathrm{Y} \sin \gamma ; \mathrm{u}_{\mathrm{y}}=\mathrm{Y}(\cos \gamma-1)\right.$ with $\gamma$ the shear angle $)$ or a biaxial tension displacement field $\left(\mathrm{u}_{\mathrm{x}}=(\alpha-1) \mathrm{X} ; \mathrm{u}_{\mathrm{y}}=(\beta-1) \mathrm{Y}\right.$ with oand $\beta$ the stretch ratios).

The material constitutive model developed in the previous section is implemented in a user subroutine of Abaqus/Explicit. The values of the material parameters are mentioned in table 2. Yarn to yarn contacts are assumed to induce Coulomb friction with a coefficient of 0.24 . The calculations have been carried out using 8 -node continuum elements with reduced integration (9600 elements for the shear simulation). The mass density is $2.53 .10^{-3} \mathrm{~g} / \mathrm{mm}^{3}$ and time steps range from $8.10^{-9}$ to $5.10^{-9}$. 


\section{Validation of mesoscopic simulations with X-ray tomography}

This section introduces the results of the simulations performed for the glass plain weave reinforcement (its specifications are given in table 1): biaxial tension and pure shear $[42,44,45]$. In this paper we focus on comparing the simulations to X-ray tomography observations so as to evaluate the deformed geometries.

Due to a slight variability of cross section shapes observed either in undeformed or biaxial tension states, it is necessary to compute average cross section shapes. Fig. 6 shows the averaged cross sections in the initial state and after an equibiaxial tension with a load of $11 \mathrm{~N}$ applied to each yarn. They are based on 30 different cross sections extracted from the sample. These cross sections can be compared to those obtained from simulation (Fig. 6). Though the initial geometry is slightly different at the tips due to the use of brick elements, the agreement is satisfying. The crushing ratios of the yarn cross section are very close: $12.5 \%$ for the simulation versus $13.3 \%$ measured by tomography.

The scans of the sheared reinforcement are performed at a scale of 2.85 microns and under a shear angle of 46 degrees. Fig. 7 shows the comparison between the scans and the simulation at the same shear angle for a sequence of transverse cross sections of the yarn. Several interesting trends are to be noticed. The computed cross section is significantly compacted along the width of the yarns as is the actual one: lowest width ratios between initial and deformed states are 0.77 for the measure by tomography versus 0.74 for the simulation. In addition, the model captures well the distortions and dissymmetries of the section due to shear of the reinforcement.

The macroscopic behavior of the reinforcement, namely the shear behavior and the biaxial tension behavior can also be obtained from these analyzes [10, 43-45]. All of these results extracted from simulations are necessary in many applications like flow simulation within deformed reinforcements $[16,17]$, finite element preforming 


\section{ACCEPTED MANUSCRIPT}

simulation [6-13]. The mesoscopic shape of the fibrous reinforcement is also very important in critical areas of the final composite [19-22].

\section{Conclusions and prospects}

An approach has been proposed for the simulation of woven composite fabric deformation at mesoscopic scale. A rate constitutive model is based on the objective derivative defined by the rotation of the fibers. The analyzes of the two point covariance performed on tomography reconstructed slices after deformation have justified a transversely isotropic model. The mechanical behavior in the transverse section is of a great importance. The "spherical" and deviatoric parts of the stress tensor are uncoupled. The first one accounts for fiber density changes and the second for shape changes.

Simulations of a plain weave unit cell deformation in biaxial tension and in-plane shear have been compared with tomography analyzes. The results are in good agreement. Further analyzes are currently performed to compare the simulations for more complex reinforcements like the interlock G1151 shown in Fig. 2.

Another on going aspect of this work is about coupling with resin flow simulation tools. The geometry of the deformed cell allows obtaining permeability values taking into account the deformation due to performing. This deformation significantly influences these values $[16,17]$.

\section{Acknowledgements}

The work reported here has been carried out in the scope of the projects ITOOL (European Commission) and MACODEV (Rhône-Alpes region).

\section{References}

1. Rudd CD, Long AC. Liquid Molding Technologies. ed. Woodhead Publishing Limited, 1997.

2. Potter KD. History of the resin transfer moulding for aerospace applications. Compos. Part A 1999; 30: 757-765.

3. Parnas RS. Liquid Composite Molding. Hanser Garner publications, 2000. 
4. Martin TA., Christie GR., Bhattacharyya D., Grid strain analysis and its application in composite sheet forming. In: Bhattacharyya D. Composite sheet forming, vol. 11. Amsterdam: Elsevier 1997.

5. Buet-Gautier K, Boisse P. Experimental analysis and modeling of biaxial mechanical behavior of woven composite reinforcements. Exp. Mech. 2001; 41(3): 260-269.

6. Hsiao SW, Kikuchi N. Numerical analysis and optimal design of composite thermoforming process. Comput. Meth. Appl. Mech. Eng. 1999; 177: 1-34.

7. Dong L, Lekakou C, Bader MG. Processing of Composites: Simulations of the Draping of Fabrics with Updated Material Behaviour Law. J. Compos. Mater. 2001; 35: 138-163.

8. Sharma SB, Sutcliffe MPF. A simplified finite element model for draping of woven material. Compos. Part A 2004; 35: 637-643.

9. Peng X, Cao J. A continuum mechanics-based non-orthogonal constitutive model for woven composite fabrics. Compos. Part A 2005; 36: 859-874.

10. Boisse P, Zouari B, Gasser A. A mesoscopic approach for the simulation of woven fibre composite forming. Compos. Sci. Technol. 2005; 65 (3-4): 429-436.

11. Gorczyca JL, Sherwood JA, Chen J. A Friction Model for use with a Commingled Fiberglass-Polypropylene Plain-Weave Fabric and the Metal Tool during Thermostamping. Eur. J. Comput. Mech. 2005; 14(6-7): 729-751.

12. ten Thije RHW, Akkerman R, Huétink J. Large deformation simulation of anisotropic material using an updated Lagrangian finite element method. Comput. Methods Applied Mech. Eng. 2007; 196(33-34): 3141-3150

13. Boisse P, Zouari B, Daniel JL. Importance of in-plane shear rigidity in finite element analyses of woven fabric composite performing. Compos. Part A 2006; 37(12): 2201-2212

14. Simacek P, Advani SG. Permeability model for a woven fabric. Polym. Compos. 1996; 17(6): 887-899

15. Takano N, Zako M, Okazaki T, Terada K. Microstructure-based evaluation of the influence of woven architecture on permeability by asymptotic homogenization theory. Compos. Sci. Technol. 2002; 62: 1347-1356

16. Laine B, Boust F, Boisse P, Hivet G, Lomov SV, Fanget A. Perméabilité des renforts fibreux. Rev. Compos. Mater. Avances 2005; 15: 385-400

17. Loix F, Badel P, Orgéas L, Geindreau C, Boisse P. Woven fabric permeability: from textile deformation to fluid flow mesoscale simulations. Compos. Sci. Technol. 2008, to appear.

18. Orgéas L, Geindreau C, Auriault JL, Bloch JF. Upscaling the flow of generalised Newtonian fluids through anisotropic porous media. J. Non-Newtonian Fluid. Mech. 2007; 145: 15-29.

19. Zako M, Uetsuji Y, Kurashiki T. Finite element analysis of damaged woven fabric composite materials. Compos. Sci. Technol. 2003; 63: 507-516.

20. Bahei-El-Din YA, Rajendran AM, Zikry MA. A micromechanical model for damage progression in woven composite systems. Int. J. Solids Struct. 2004; 41: 2307-2330.

21. Pickett AK, Fouinneteau MRC. Material characterisation and calibration of a mesomechanical damage model for braid reinforced composites. Compos. A 2006; 37: 368-377.

22. Ladevèze $P$, Lubineau G, Marsal $D$. Towards a bridge between the micro- and mesomechanics of delamination for laminated composites. Comp. Sci. Tech.. 2006; 66: 698-712.

23. Lomov S, Ivanov DS, Verpoest I, Zako M, Kurashiki T, Nakai H, Hirosawa S, Meso-FE modelling of textile composites: road map, data flow and algorithms, Compos. Sci. Technol. 2007; 67: 1870-1891.

24. Baruchel J, Buffiere JY, Maire E, Merle P, Peix G. X ray tomography in material science. Paris: Hermès (eds), 2000. 
25. F. Desplentere, S.V. Lomov, D.L. Woerdeman, I. Verpoest, M. Wevers, A. Bogdanovich. Micro-CT characterization of variability in 3D textile architecture, Compos. Sci. Technol. 2005; 65: 1920-1930.

26. Truesdell C. Hypo-elasticity. J. Rat. Mech. Anal. 1955; 4: 83-133.

27. Truesdell C. The simplest rate theory of pure elasticity. Comm. Pure Appl. Math. 1955; 8: 123-132.

28. Xiao H, Bruhns OT, Meyers A. Hypo-elasticity model based upon the logarithmic stress rate. J. Elasticity 1997; 47: 51-68.

29. Xiao H, Bruhns OT, Meyers A. On objective corotational rates and their defining spin tensors. Int. J. Solids Struct. 1998; 35(30): 4001-4014.

30. web site: http://www.phoenix-xray.com/en/applications/3d_computed_tomography/

31. Doumalin P, Bornert M, Crépin J. Characterisation of the strain distribution in heterogeneous materials. Mécanique \& Industries 2003; 4 (6): 607-617.

32. Delarue A, Jeulin D. 3D morphological analysis of composite materials with aggregates of spherical inclusions. Image Anal. Stereol. 2003; 22: 153-161.

33. Hughes TJR, Winget J. Finite rotation effects in numerical integration of rate constitutive equations arising in large deformation analysis. Int. J. Num. Meth. Eng. 1980; 15: 18621867.

34. Criesfield MA. Non linear Finite Element Analysis of Solids and Structure: Advanced Topics, Volume 2. Chichester: John Wiley Edt., 1997.

35. Belytschko T, Wing KL, Moran B. Nonlinear Finite Elements for Continua and Structures. Chichester: John Wiley Edt., 2000.

36. Lebail H. Caractérisations microscopiques et mécaniques de matériaux composites et étude des relations aux propriétés élastiques associées. PhD Thesis, INSA Lyon, 2001.

37. Hagège B, Boisse P, Billoët JL. Finite element analyses of knitted composite reinforcement at large strain, Eur. J. Comput. Mech. 2005; 14: 767-776

38. Boisse P, Gasser A, Hagege B, Billoet JL. Analysis of the mechanical behavior of woven fibrous material using virtual tests at the unit cell level. J. Mater. Sci. 2005; 40 5955-5962.

39. Cai Z, Gutowski T. The 3-D deformation behavior of a lubricated fiber bundle. J. Compos. Mater. 1992; 26: 1207-1237.

40. Simacek P, Karbhari VM. Notes on the modeling of preform compaction: I-micromechanics at the fiber bundle level, J. Reinf. Plast. Compos. 1996; 15: 86-122

41. Schnur DS, Zabaras N. An inverse method for determining elastic material properties and a material interface, Int. J. Numer. Meth. Engrg. 1992; 33: 2039-2057.

42. Gasser A, Boisse P, Hanklar S. Mechanical behaviour of fry fabric reinforcements. 3D simulations versus biaxial test. Comp. Mater. Sci. 2000; 17: 7-20.

43. Hivet G, Boisse P. Consistent 3D geometrical model of fabric elementary cell. Application to a meshing preprocessor for 3D finite element analysis. Finite Elem. Anal. Des. 2005; 42: $25-49$.

44. Badel P, Vidal-Sallé E, Boisse P. Computational determination of in-plane shear mechanical behaviour of textile composite reinforcements. Comput. Mater. Sci. 2007; 40(4): 439-448.

45. Badel P, Vidal-Sallé E, Boisse P. Large deformation analysis of fibrous materials using rate constitutive equations. Comput. Struct. 2008, to appear. 


\section{ACCEPTED MANUSCRIPT}

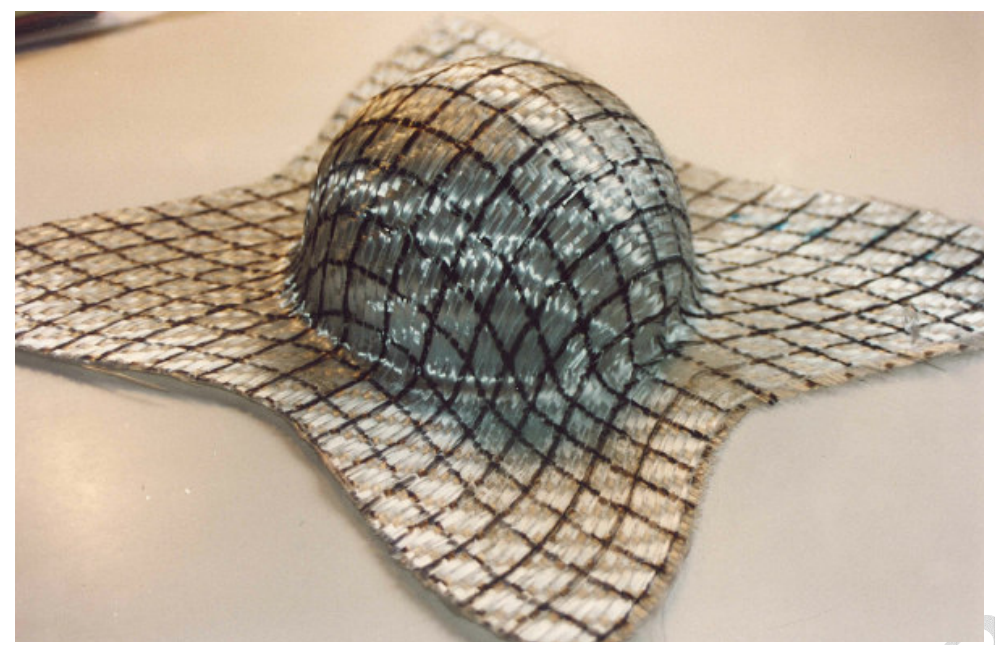

Figure 1. Hemispherical preforming of a woven composite reinforcement. A

network of initially straight and continuous orthogonal lines has been drawn on the initial flat reinforcement.

(a)
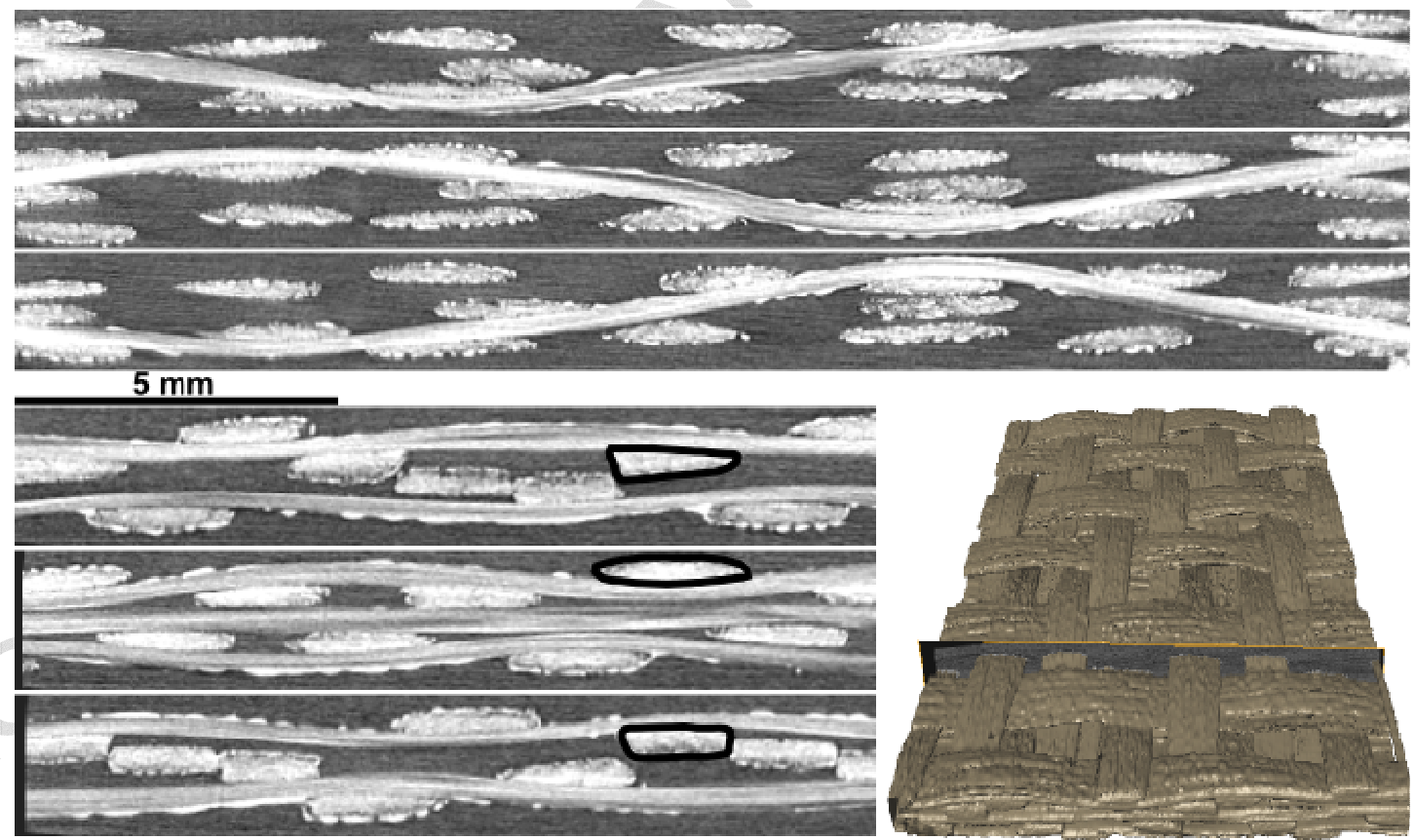

Figure 2. Unloaded interlock reinforcement G1151 (20 $\mu \mathrm{m}$ resolution, rescaled). (a)

Three successive slices within warp yarn planes and (b) Three successive slices within weft planes. Three cross sections of the same yarn are underlined in black. 


\section{ACCEPTED MANUSCRIPT}

(a)

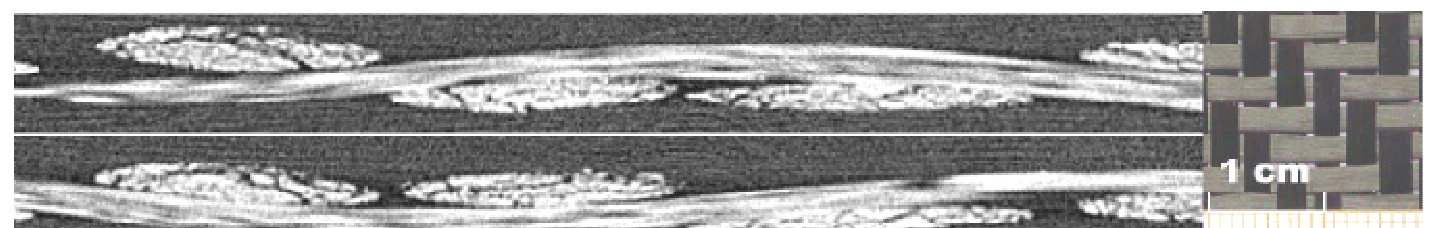

(b)
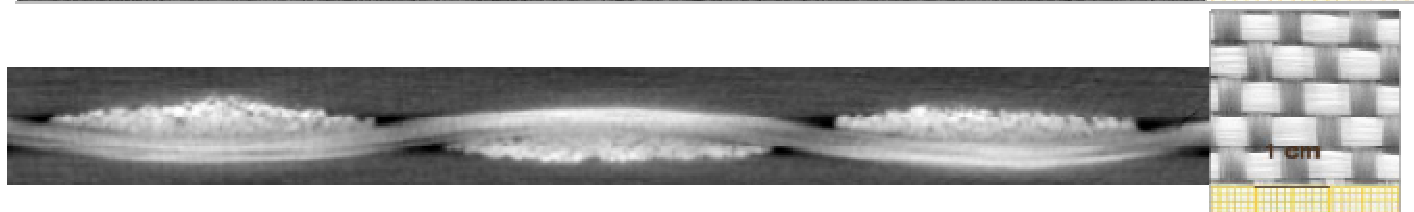

Figure 3. (a) Two reconstructed slices of a carbon $2 \times 2$ twill (10 $\mu \mathrm{m}$ resolution,

rescaled) in the planes of two successive yarns. (b) Reconstructed slice of a glass plain weave under $11 \mathrm{~N}$ biaxial tension $(20 \mu \mathrm{m}$ resolution, rescaled).

(a)

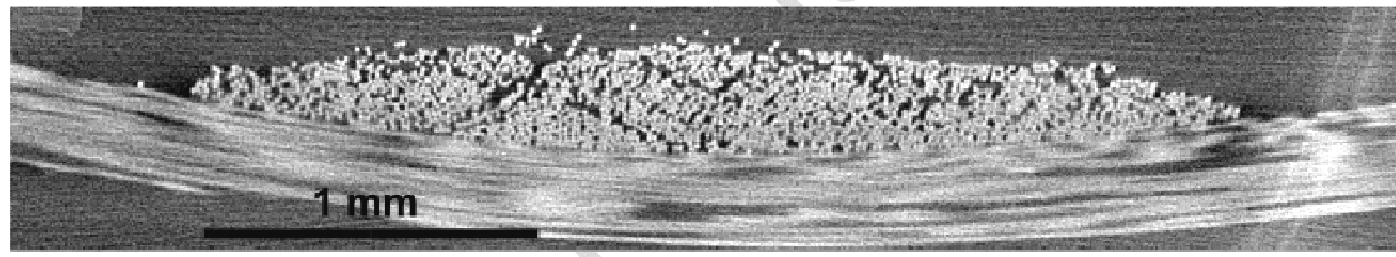

(b)

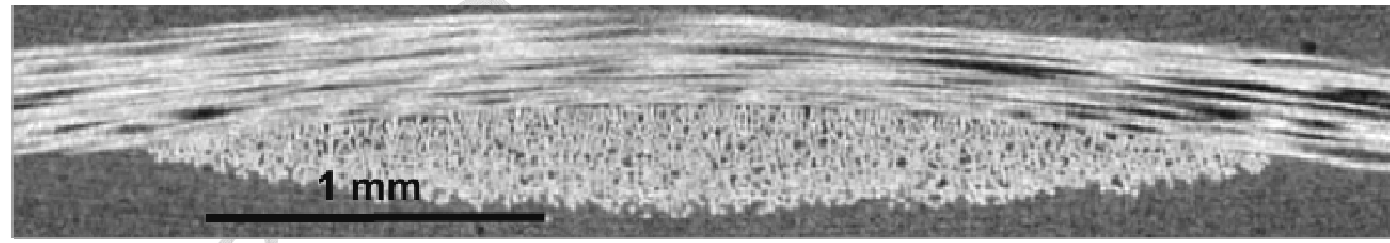

$$
\operatorname{con} 2
$$

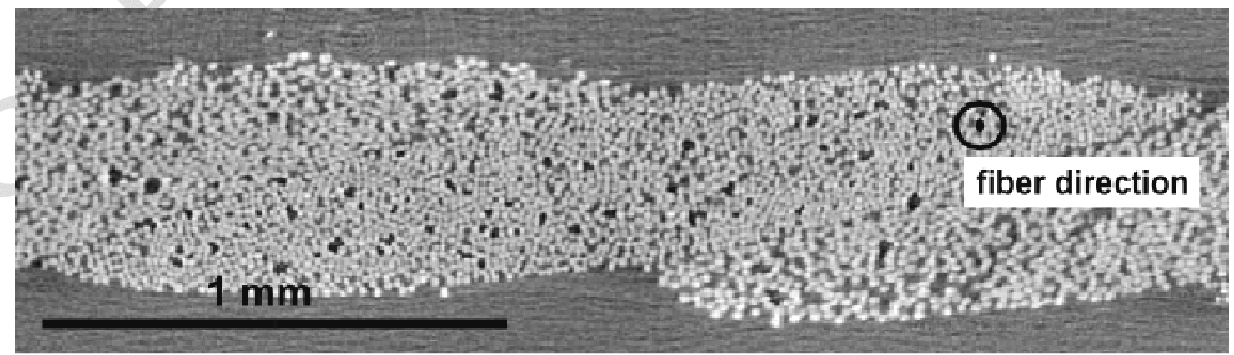

(c)

Figure 4. Glass plain weave (a) unloaded ( $3 \mu \mathrm{m}$ resolution, rescaled) (b) biaxial tension (5 $\mu \mathrm{m}$ resolution) and (c) $46^{\circ}$ pure shear $(2.85 \mu \mathrm{m}$ resolution rescaled) 


\section{ACCEPTED MANUSCRIPT}

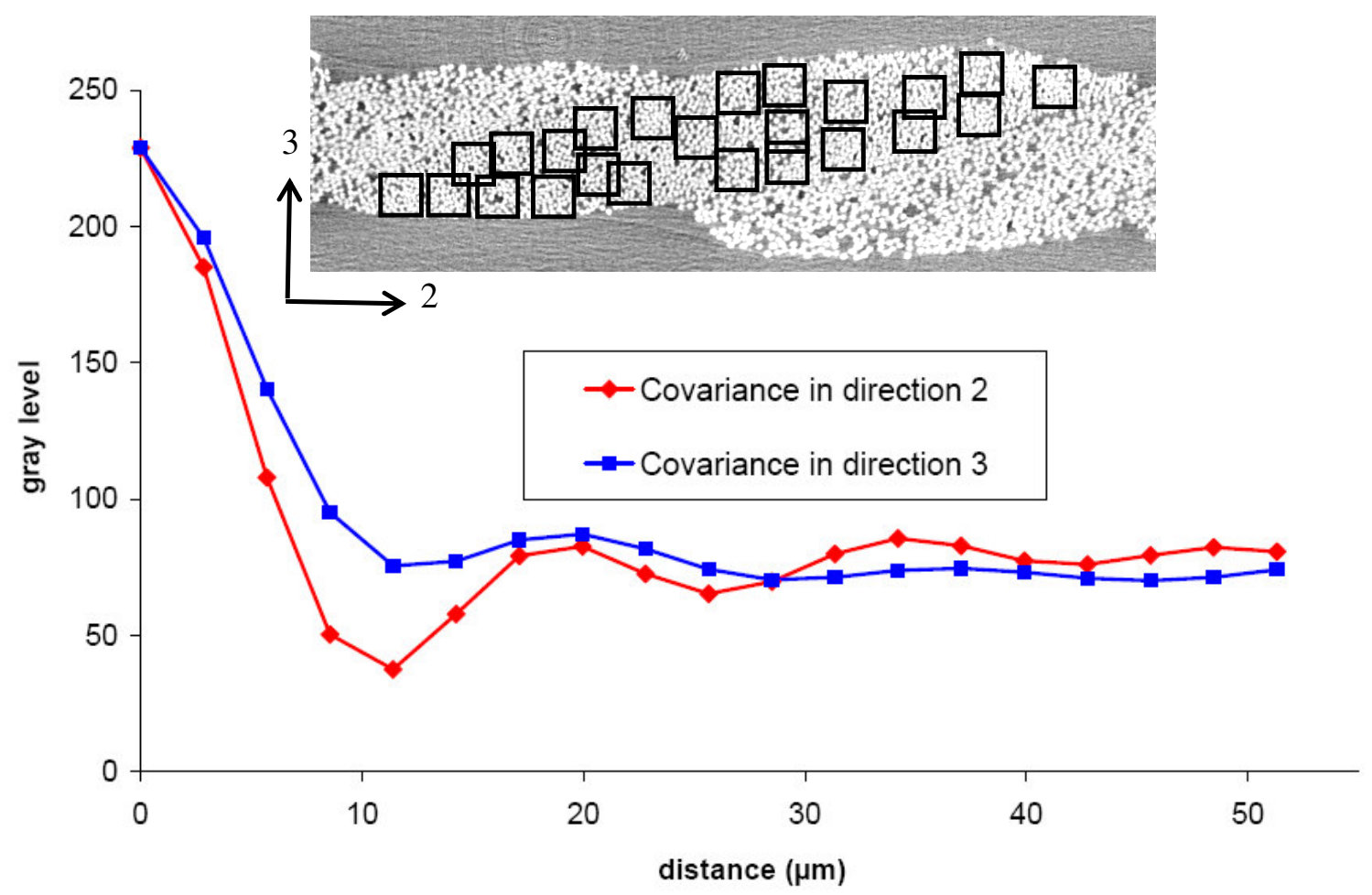

Figure 5. Average covariance in direction 2 and 3 computed from 90 observation zones

(black squares on this slice) extracted from four slices of deformed yarns.

(a)

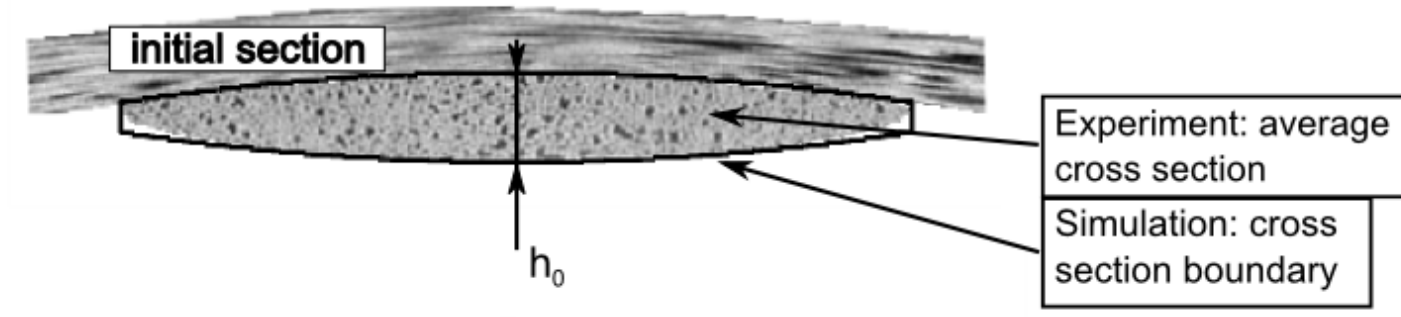

(b)

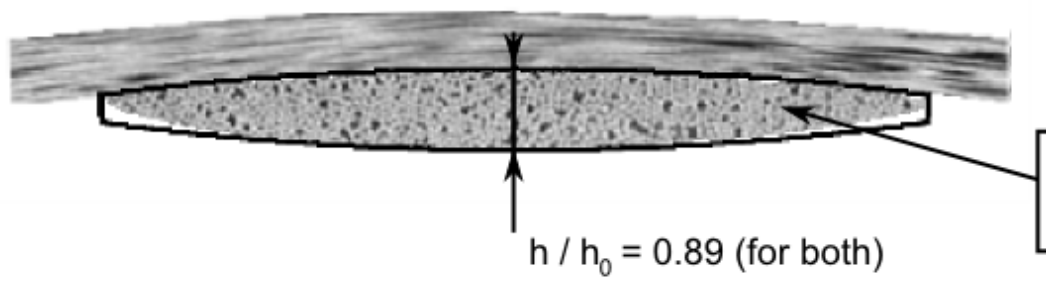

Experiment: $\mathrm{S} / \mathrm{S}_{0}=0.86$

Simulation: $\mathrm{S} / \mathrm{S}_{0}=0.87$

Figure 6. Biaxial tension test, simulation vs experiment. (a) initial yarn cross section

(b) yarn cross section under biaxial tension, with ratios of area and thickness. 

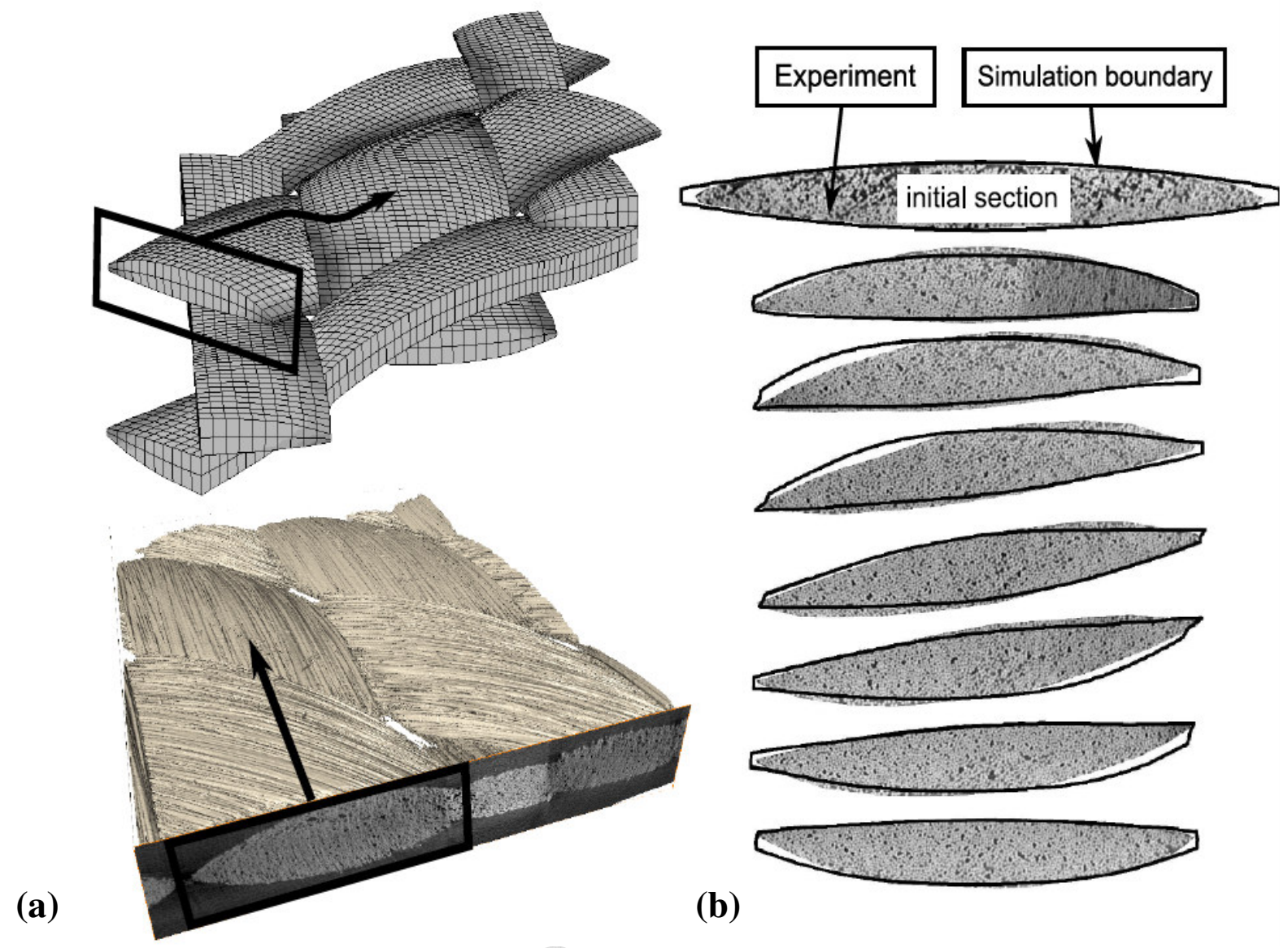

Figure 7. Pure shear: comparison of simulation with CT scans: (a) deformed shape of the unit cell (b) set of yarn cross sections along half a period of the yarn. 


\section{ACCEPTED MANUSCRIPT}

Table 1. Plain weave and 2x2 twill and G1151 specifications

\begin{tabular}{|l|c|c|c|}
\hline Weaving & Glass plain weave & Carbon 2 x 2 twill & G1151 (interlock) \\
\hline Yarn width (mm) & Warp: 3,4 & Warp: 2,4 & Warp: 1,9 \\
& Weft: 3,4 & Weft: 2,4 & Weft: 2,2 \\
\hline Densities (Yarn/mm) & Warp: 0,25 & Warp: 0,35 & Warp: 0.75 \\
& Weft: 0,25 & Weft: 0,35 & Weft: 0,6 \\
\hline Crimp (\%) & Warp: 0,55 & Warp: 0,3 & Warp: 1,2 \\
& Weft: 0,55 & Weft: 0,35 & Weft: 0,5 \\
\hline Yarn stiffness (N) & 47000 & 54000 & \\
\hline
\end{tabular}

Table 2. Material parameters used in the constitutive matrix for glass plain weave simulations.

\begin{tabular}{|l|c|}
\hline Longitudinal Young modulus $\mathrm{E}_{1}(\mathrm{MPa})$ & 52500 \\
\hline Transverse parameter $\mathrm{A}_{0}(\mathrm{MPa})$ & $1.86 \mathrm{E}-3$ \\
\hline Transverse parameter $\mathrm{B}_{0}(\mathrm{MPa})$ & $6.25 \mathrm{E}-3$ \\
\hline Transverse parameter $\mathrm{n}$ & 4060 \\
\hline Transverse parameter $\mathrm{p}$ & 39.9 \\
\hline Longitudinal shear modulus $\mathrm{G}_{1}(\mathrm{MPa})$ & 20 \\
\hline
\end{tabular}

